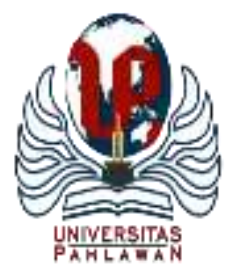

Edukatif : Jurnal Ilmu Pendidikan Volume 4 Nomor 1 Tahun 2022 Halm 675 - 685

EDUKATIF: JURNAL ILMU PENDIDIKAN

Research \& Learning in Education

https://edukatif.org/index.php/edukatif/index

\title{
Dampak Kebijakan Merdeka Belajar Kampus Merdeka (MBKM) pada Perguruan Tinggi Swasta di Indonesia
}

\author{
Konstantinus Denny Pareira Meke ${ }^{1 凶}$, Richardo Barry Astro ${ }^{2}$, Maimunah H. Daud ${ }^{3}$ \\ Program Studi Pendidikan Matematika,, Indonesia ${ }^{1}$, \\ Program Studi Pendidikan Fisika, Indonesia ${ }^{2}$, \\ Program Studi Pendidikan Biologi, Indonesia ${ }^{3}$ \\ E-mail : dennyz.pareira@gmail.com ${ }^{1}, \underline{\text { richardobarryastro@gmail.com }}{ }^{2}, \underline{\text { maimunahhdaud@gmail.com }}^{3}$
}

\begin{abstract}
Abstrak
Merdeka Belajar Kampus Merdeka (MBKM) adalah program pembelajaran pendidikan tinggi yang mandiri dan serbaguna yang dirancang untuk menciptakan komunitas pembelajaran kreatif yang tidak membatasi yang memenuhi kebutuhan mahasiswa Penelitian ini bertujuan untuk untuk melihat dampak dan persepsi penerapan Merdeka Belajar Kampus Merdeka (MBKM) kepada seluruh mahasiswa di perguruan tinggi swasta dengan tujuan untuk melihat sejauh mana pemahaman dan persepsi mahasiswa dan dampak dari penerapan program Merdeka Belajar Kampus Merdeka (MBKM) yang ada di Perguruan Tinggi. Penelitian ini merupakan penelitian deskriptif dengan pendekatan kuantitatif dengan metode survei. Data diperoleh dari populasi yakni 96 responden yang merupakan mahasiswa Program Studi Pendidikan Biologi Universitas Flores. Data dikumpulkan melalui kuesioner. Teknik analisis data dimulai dari pengumpulan data kemudian dianalisis menggunakan analisis deskriptif. Hasil dari penelitian survei ini menunjukan bahwa mahasiswa pada program studi pendidikan biologi, Fakultas Keguruan dan Ilmu Pendidikan (FKIP) Universitas Flores memberikan respon yang positif terhadap program Merdeka Belajar Kampus Merdeka (MBKM).
\end{abstract}

Kata Kunci: kebijakan, Merdeka Belajar Kampus Merdeka (MBKM), perguruan tinggi swasta.

\begin{abstract}
Independent Learning-Independent Campus (MBKM) is an independent and versatile higher education learning program designed to create an unrestricted creative learning community that meets the needs of students. all students in private universities to see the extent of student understanding and perception and the impact of implementing the Independent Learning-Independent Campus (MBKM) program in universities. This research is descriptive research with a quantitative approach with a survey method. Data were obtained from the population, namely 96 respondents who were students of the Biology Education Study Program, University of Flores. Data were collected through a questionnaire. The data analysis technique started from data collection and then analyzed using descriptive analysis. The results of this survey research show that students in the biology education study program, Faculty of Teacher Training and Education (FKIP) the University of Flores gave a positive response to the Independent Learning-Independent Campus (MBKM) program.
\end{abstract}

Keywords: policy, Independent Learning Independent Campus, private university

Copyright (c) 2022 Konstantinus Denny Pareira Meke, Richardo Barry Astro, Maimunah H. Daud

$\triangle$ Corresponding author

Email : dennyz.pareira@ gmail.com

DOI : https://doi.org/10.31004/edukatif.v4i1.1940

ISSN 2656-8063 (Media Cetak)

ISSN 2656-8071 (Media Online) 


\section{PENDAHULUAN}

Media komunikasi, ilmu pengetahuan dan teknologi kini menjadi media yang berkembang dengan begitu pesat. Hal ini menuntut individu untuk terus mampu menyesuaikan pribadi mereka dengan mengasah skill dan potensi diri agar mampu menyesuaikan dengan kemajuan zaman. Mahasiswa sebagai orang muda turut menjadi salah satu individu yang dituntut untuk mampu bersaing nantinya dalam dunia kerja. Pemerintah sndiri juga terus berupaya untuk memajukan dan mencari metode yang baik untuk perubahan dalam dunia pendidikan dan dunia kerja, sehingga kelak para mahasiswa mampu menhadapi dunia kerja dengan kompetensi di bidang keahlian sesuai kebutuhan dunia kerja (Kamalia \& Andriansyah, 2021).

Berbagai kebijakan dan kajian dilakukan oleh pemerintah dan perguruan tinggi guna memperoleh relevansi pengajaran, pelatihan, dan pendidikan di perguruan tinggi dalam merespon kemajuan tersebut. Kajian tentang kebijakan tersebut tentu harus memperhatikan ilmu pengetahuan dan tuntutan dunia kerja, serta kehidupan kampus dan hubungannya dengan sosial budaya dalam kehidupan bermasyarakat dan bernegara yang nantinya sebagai upaya membangun generasi yang berpotensi (Rosmiati, Putra \& Nasori, 2021).

Kebijakan Merdeka Belajar Kampus Merdeka (MBKM) menjadi salah satu kajian kebijakan yang tengah digalakan pemerintah untuk diterapkan pada dunia pendidikan perguruan tinggi. MBKM adalah mode pembelajaran pendidikan tinggi yang mandiri dan serbaguna yang dirancang untuk menciptakan komunitas pembelajaran kreatif yang tidak membatasi yang memenuhi kebutuhan mahasiswa (Rochana, Darajatun \& Ramdhany, 2021). Program MBKM merupakan revolusi pendidikan yang berdasarkan pada perkembanngan industri 4.0 (Syarifuddin, dkk, 2021:20). Kebijakan MBKM diatur pada Peraturan Menteri Pendidikan dan Kebudayaan Nomor 3 Tahun 2020 tentang Standar Nasional Perguruan Tinggi, khususnya Pasal 15 sampai dengan 18. MBKM bertujuan untuk mendorong mahasiswa memperoleh pengalaman belajar dengan berbagai kompetensi tambahan. di program studi dan/atau di luar kampus (Junaidi, dkk., 2020).

Kebijakan MBKM bertujuan untuk mewujudkan manusia yang berdaya saing; Artinya, manusia sehat, cerdas, adaptif, kreatif, inovatif, terampil, bermartabat, produktif, dan berkarakter sesuai dengan nilai-nilai Pancasila (Sodik, Purwiyanta \& Wijayanti, 2021). Instrumen penting implementasinya adalah dengan menerapkan delapan Indikator Kinerja Utama (IKU) yang telah ditetapkan melalui Keputusan Menteri Pendidikan dan Kebudayaan nomor 754/P/2020.Universitas Flores, melalui SK Rektor no. 2 Tahun 2021 turut berpartisipasi dalam program kebijakan MBKM.

Sejalan dengan hal tersebut, Program Studi Pendidikan Biologi, FKIP Universitas FLores dalam prosesnya terus berusaha agar bisa mengikuti kebiajakan program MBKM tersebut. Program studi Pendidikan Biologi di Universitas Flores memiliki program kegiatan yang telah berjalan dan yang serupa dengan program kegiatan MBKM diantaranya program mahasiswa mengajar di Satuan pendidikan atau yang dikenal dengan Praktik Pengalaman Lapangan (PPL), KKN Tematik dan juga riset/penelitian (Fatah, 2021; Kurnia, dkk 2021). Namun dalam pelaksanaannya, kegiatan tersebut diberlakukan untuk pemenuhan sks yang telah tersedia pada program studi. Pemahaman mahasiswa tentang MBKM tentu menjadi kunci bagi suksesnya program MBKM (Putri, dkk., 2021; Zunaidi, Fatmawatie, Natalina \& Mushlihin. 2021). Lebh lanjut strategi merdeka belajar tentu harus diimbangi dengan perubahan pemahaman dari para mahasiswa yang diikuti dengan perubahan kebiasaan dalam pengelolaan pembelajaran dan melaksanakan tri dharma lainnya (Zunaidi, Fatmawatie, Natalina \& Mushlihin. 2021).

Berdasarkan latar belakang tersebut dan merespon akan diterapkannya konsep kampus merdeka, maka dirasa perlu untuk dilakukan penelitian mengenai dampak dari diterapkannya kebijakan MBKM untuk melihat sejauh mana kinerja dari Universitas dalam menyiapkan mahasiswanya (Aji \& Putra, 2021; Intan Dzikria, \& Luvia Friska Narulita, 2021).). Lebih lanjut, selain untuk mngukur kinerja program studi khusunya, penelitian ini juga bertujuan untuk memperoleh hasil yang dapat digunakan oleh program studi dan universitas serta tim Ditjen Dikti Ristek untuk mengevaluasi dan melakukan pengembangan kurikulum dan desain pembelajaran 
677 Dampak Kebijakan Merdeka Belajar Kampus Merdeka (MBKM) pada Perguruan Tinggi Swasta di Indonesia - Konstantinus Denny Pareira Meke, Richardo Barry Astro, Maimunah H. Daud

DOI: https://doi.org/10.31004/edukatif.v4i1.1940

guna mewujudkan capaian pembelajaran yang optimal (Nasik, 2021). Sejauh ini belum banyak ditemukan penelitian yang mendeskripsikan hasil implementasi pembelajaran MBKM karena program ini baru dirilis, oleh karena itu, tim survei MBKM Universitas Flores bekerjasama dengan Kementrian Pendidikan, Kebudayaan, Riset dan Teknologi, melakukan penelitian untuk melihat dampak dan persepsi penerapan MBKM kepada seluruh mahasiswa program studi pendidikan biologi dengan tujuan untuk melihat sejauh mana pemahaman dan persepsi mahasiswa program studi pendidikan biologi dan dampak dari penerapan program MBKM yang ada di Universitas Flores.

\section{METODE PENELITIAN}

Penelitian ini merupakan penelitian deskriptif dengan pendekatan kuantitatif (Arikunto 2010), dengan metode survei. Data diperoleh dari populasi yakni 96 responden yang merupakan mahasiswa Program Studi Pendidikan Biologi Universitas Flores. Data dikumpulkan melalui kuesioner yang telah dibuat oleh Kementrian Pendidikan, Kebudayaan, Riset dan Teknologi melalui aplikasi SPADA Dikti. Teknik analisis data dimulai dari pengumpulan data kemudian dianalisis menggunakan analisis deskriptif. Data yang dianalisis bersumber dari data Primer melalui pemetaan hasil tiap butir pertanyaan yang digunakan dalam kuesioner. Semua analisis menggunakan standar baku yakni diagram hasil jawaban dari mahasiswa yang disajikan menggunakan informasi data statistik (Bethlehem 2009).

Dari setiap butir penelitian yang akan disimpulkan secara prosedural, hasil penelitian ini akan digunakan sebagai adaptasi atas kajian kegiatan merdeka belajar kampus merdeka tentang perencanaan, proses pembelajaran, penilaian dan evaluasi pembelajaran. Lebih lanjut, hasil penelitian ini akan digunakan untuk melihat kesesuaian terhadap kurikulum program studi yang telah ada serta menjadi acuan untuk merancang proses pembelajaran serta kerjasama akademik yang relevan (Baharuddin, 2021).

\section{HASIL DAN PEMBAHASAN PENELITIAN}

Penelitian ini dilakukan untuk mengukur persepsi dan dampak dari penerapan MBKM Program Studi Pendidikan Biologi, Universitas Flores. Responden yang dipilih merupakan seluruh populasi mahasiswa pada Program Studi Pendidikan Biologi, FKIP Universitas Flores.

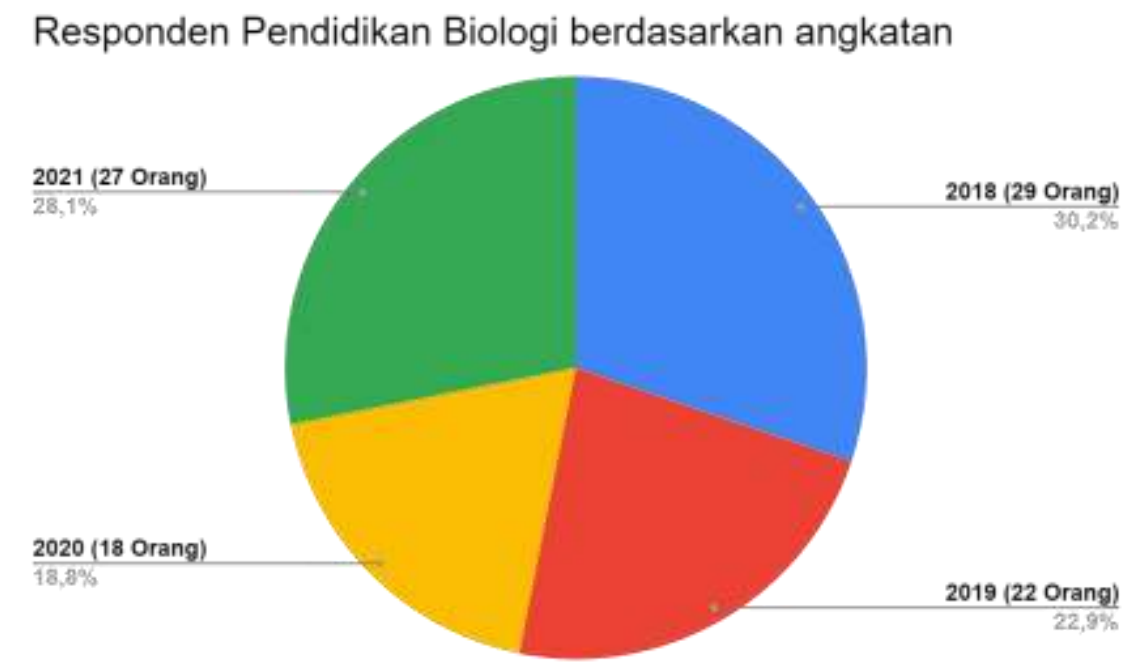

Gambar 1: Gambaran Responden (Mahasiswa) Program Studi Pendidikan Biologi 
678 Dampak Kebijakan Merdeka Belajar Kampus Merdeka (MBKM) pada Perguruan Tinggi Swasta di Indonesia - Konstantinus Denny Pareira Meke, Richardo Barry Astro, Maimunah H. Daud

DOI: https://doi.org/10.31004/edukatif.v4i1.1940

Hasil penelitian ini menggunakan metode survei dengan penjelasan deskriptif kualitatif yang dianalisis menggunakan informasi data statistik. Survei ini sendiri terdiri dari 22 butir pertanyaan dan pernyataan dengan pilihan jawaban yang disesuaikan dengan kebutuhan survey oleh tim SPADA Dikti. Survei akan terbagi dalam 2 bagian tergantung dari siswa memilih jawaban pada butir pertanyaan pertama kuesioner yang diberikan dalam online kuesioner. Bagian pertama ialah mahasiswa yang yang menjawab kuesioner butir pertama mengetahui kebijakan baik seluruhnya, sebagian besar isi kebijakan maupun sedikit mengetahui, akan melanjutkan jawaban kuesioner ke nomor 2 hingga 22 yakni berupa permintaan kritik dan saran. Namun, jika mahasiswa menjawab belum mengetahui kebijakan MBKM pada butir pertama, maka mahasiswa tersebut akan melewati tahap pertanyaan 2 - 21, dan langsung menjawab butir 22 yakni permintaan kritik dan saran untuk kemajuan penerapan kebijakan MBKM.

Berdasarkan hasil pemetaan survei yang diperoleh dari data, diperoleh hasil sebagai berikut:

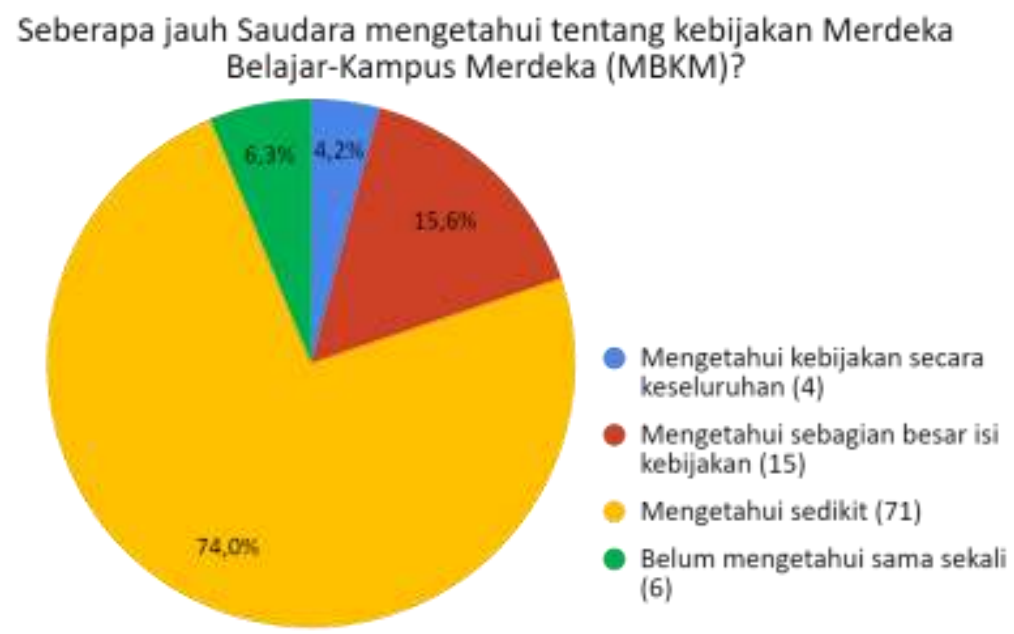

\section{Gambar 2: Hasil Survei untuk Pengetahuan Mahasiswa Mengenai Kebijakan MBKM}

Gambar 2 diperoleh dari analisis untuk melihat sejauh mana mahasiswa Program Studi Pendidikan Biologi mengetahui mengenai Kebijakan MBKM. Hasil survei menunjukan 71 mahasiswa dari total survei 96 responden mahasiswa menjadi yang paling banyak dipilih yakni sedikit mengetahui tentang program kebijakan MBKM. 15 mahasiswa menjawab mengetahui sebagian besar isi kebijakan dan 4 responden menjawab mengetahui secara keseluruhan. Sementara itu 6 responden mahasiswa menjawab belum mengetahui tentang MBKM. Berdasarkan pilihan tersebut maka 6 mahasiswa tidak akan mengikuti survei lanjutan di pilihan butir 2-21, dan 90 responden melanjutkan untuk pertanyaan 2 -22.

Lebih lanjut untuk butir kuesioner 2 dan 3 . Tim memberikan pertanyaan ujicoba mengenai pengetahuan siswa mengenai jumlah semester dan sks yang dapat diambil oleh mahasiswa jika ingin melanjutkan atau memilih kuliah di prodi luar perguruan tinggi. Pada tes ini, terdapat 7 mahasiswa $(7,8 \%)$ dari 90 responden mahasiswa menjawab secara tepat. Hal ini menunjukan progress sosialisasi yang perlu dilakukan lebih giat (Baharuddin, 2021; Fuadi, 2021), ditambah bentuk kebiiakan kuliah di luar Perguruan Tinggi untuk program MBKM belum diterapkan pada Program Studi Pendidikan Biologi Universitas Flores, sehingga mahasiswa belum menaruh perhatian lebih pada poin pertanyaan ini.

Lebih lanjut pada butir kuisioner mengenai platform yang digunakan oleh responden untuk memperoleh informasi tentang segala kebijakan MBKM, diperoleh hasil yang ditunjukan pada gambar 3 berikut: 
679 Dampak Kebijakan Merdeka Belajar Kampus Merdeka (MBKM) pada Perguruan Tinggi Swasta di Indonesia - Konstantinus Denny Pareira Meke, Richardo Barry Astro, Maimunah H. Daud

DOI: https://doi.org/10.31004/edukatif.v4i1.1940

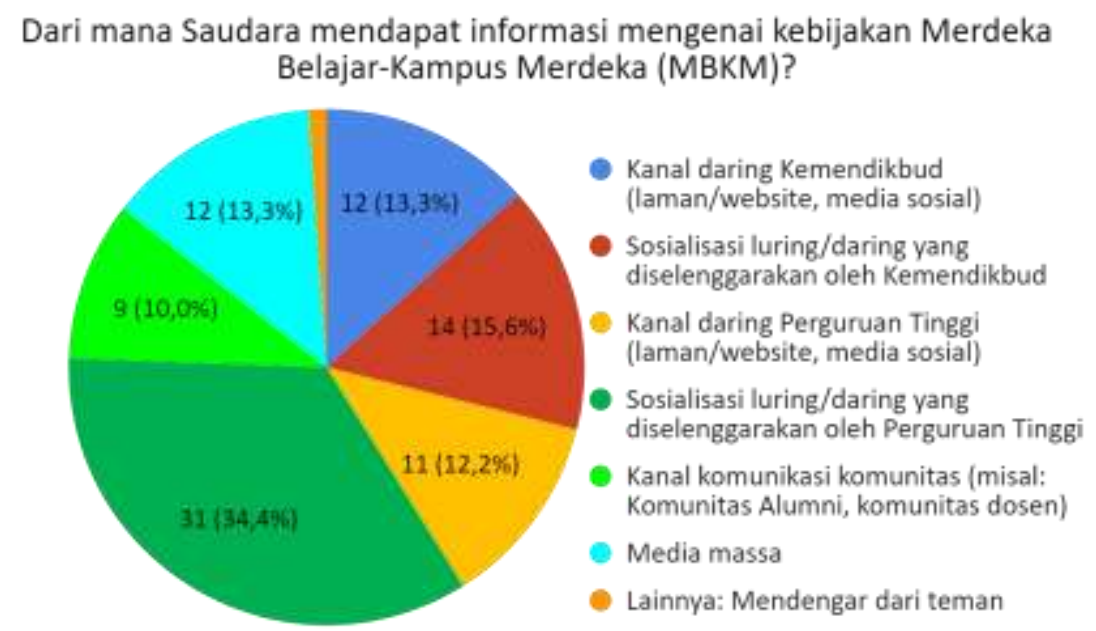

\section{Gambar 3: Hasil Survei Mengenai Platform Informasi Kebijakan MBKM}

Gambar 3 menunjukan 31 responden mahasiswa memilih bentuk sosialisasi oleh perguruan tinggi sebagai platform yang mereka gunakan untuk mendapatkan informasi mengenai MBKM. Lebih lanjut sejalan dengan hasil pada gambar 3, 61 dari 90 responden $(26,0 \%)$ responden mahasiswa menyatakan bahwa media informasi yang paling dipilih untuk meningkatkan pemahaman mereka mengenai kebijakan MBKM ialah sosialisasi daring maupun luring yang digunakan oleh perguruan tinggi. Hal ini menunjukan pentingnya sosialisasi dalam penerapan MBKM yang dilakukan Perguruan Tinggi sebagai tempat mahasiswa belajar (Baharuddin, 2021; Fuadi \& Aswita 2021).

Lebih lanjut, hasil penelitian juga menunjukan bahwa 90\% responden menjawab sangat tertarik untuk mengikuti program MBKM yang diadakan olehDirektorat Jendral Pendidikan Tinggi, Riset dan Teknologi

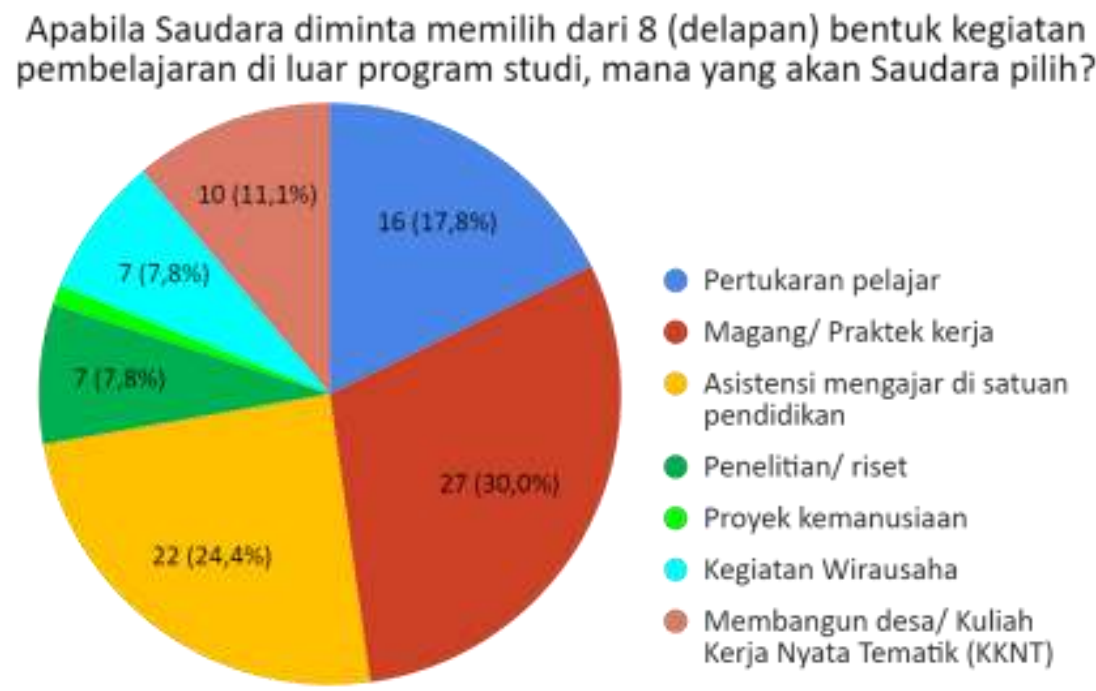

\section{Gambar 4: Hasil Pilihan Responden Mengenai Program MBKM}

Pada butir kuesioner berikutnya, ketika responden diminta untuk memilih program MBKM yang ingin diikuti, yang paling banyak diminati ialah program magang/praktek kerja. Hal ini ditunjukan pada grafik gambar 4 dimana 27 responden mahasiswa memilih program tersebut. Pilihan ini cukup berbeda dengan bentuk program kuliah sebelum MBKM diterapkan dimana program magang /praktek kerja tidak terdapat 
680 Dampak Kebijakan Merdeka Belajar Kampus Merdeka (MBKM) pada Perguruan Tinggi Swasta di Indonesia - Konstantinus Denny Pareira Meke, Richardo Barry Astro, Maimunah H. Daud

DOI: https://doi.org/10.31004/edukatif.v4i1.1940

pada program studi pendidikan biologi. Hal ini mungkin dikarenakan suasana baru yang ingin dirasakan oleh responden dan melihat magang sebagai kesempatan dalam mengaplikasikan teori-teori yang telah dipelajari di perkuliahan, serta penerapan keterampilan umum dan khusus di dunia kerja. Magang juga dirasa dapat meningkatkan kompetensi, kemampuan, dan memberikan pengalaman nyata yang komprehensif sehingga dapat membiasakan diri mereka untuk siap terjun ke dunia kerja pada masa mendatang (Aswita 2021). Sementara itu pilihan kedua terbanyak yakni mengajar di satuan Pendidikan. Hal ini dirasa wajar karena program ini sesuai dengan basic dan bidang ilmu dari program studi sendiri, yakni sebagai calon guru.

Apakah Saudara sudah menyiapkan diri untuk menjadi bagian dalam kegiatan MBKM?

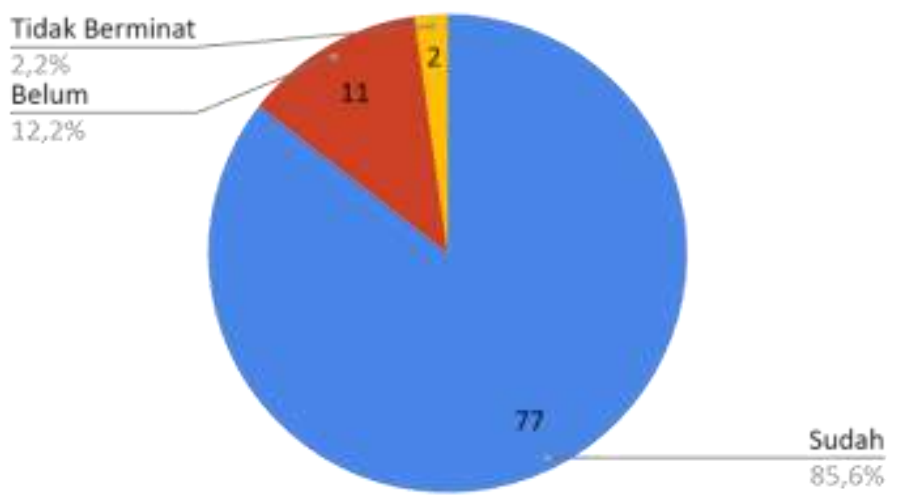

\section{Gambar 5: Hasil Jawaban Survei Mengenai Kesiapan Mahasiswa dalam Mengikuti Kebijakan MBKM}

Lebih lanjut, gambar 5 menunjukan bahwa pada indikator kesiapan responden terhadap kebijakan program MBKM, 85,6\% resoponden (77 mahasiswa pendidikan biologi) menyatakan telah menyiapkan diri untuk mengikuti program MBKM. Respon ditunjukan dengan minat mahasiswa dalam mendaftar pada program kebijakan MBKM yang diberikan. Lebih lanjut studi diluar kampus menjadi alasan siswa sangat merespon dan siap untuk mengikuti kegiatan MBKM. Mahasiswa merasa merdeka untuk memilih bidang belajar diluar kampus yang mereka minati. Hal ini menunjukan bahwa kampus merdeka memberikan wujud pembelajaran di yang otonom dan fleksibel yang dapat dilakukan mahasiswa di luar ruang kelas, bahkan diluar perguruan tingginya, sehingga tercipta kebiasaan belajar yang inovatif, dan sesuai dengan kebutuhan mahasiswa serta mendapatkan banyak koneksi atau teman diluar kelasnya sendiri (Sopiansyah, Masruroh, Zaqiah \& Erihadiana, 2021)

Respon positif terhadap kebijakan MBKM juga ditunjukan pada butir kuesioner yang menanyakan tentang implikasi waktu kuliah akibat pembelajaran yang dilakukan di luar program studi.65,9\% responden yakin bahwa waktu perkuliahan akan tetap dapat diselesaikan tepat waktu. Selanjutnya 76 responden dari 90 responden $(84,4 \%)$ yakin bahwa kegiatan pembelajaran diluar kampus akan memberikan kompetensi tambahan seperti keterampilan dalam menyelesiakan permasalahan nyata yang kompleks,keterampilan dalam menganalisis dan etika dalam profesi kerja. Hal ini juga sejalan denga hasil survei jawaban pada butir kuesioner selanjutnya, dimana 65,6\% responden dominan setuju atas pernyataan bahwa program MBKM untuk belajar deprogram studi lain akan memperluas perspektif dan memberikan kompetensi tambahan yang dibutuhkan oleh mahasiswa. Respon positif ini menunjukan bahwa responden memberikan minta yang dan perhatian terhadap program kebijakan MBKM ini (Baharuddin, 2021; Rochana, Darajatun \& Ramdhany, 2021). 
681 Dampak Kebijakan Merdeka Belajar Kampus Merdeka (MBKM) pada Perguruan Tinggi Swasta di Indonesia - Konstantinus Denny Pareira Meke, Richardo Barry Astro, Maimunah H. Daud

DOI: https://doi.org/10.31004/edukatif.v4i1.1940

Respon positif masih terus ditunjukan oleh responden pada pilihan butir kuesioner berikutnya, dimana dari total 90 responden, 71 responden menyatakan sangat bermanfaat dan 19 responden menyatan cukup bermanfaat pada pernyataan kebermanfaatan program kebijakan MBKM dalam meningkatkan kompetensi/keterampilansebagai bekal kerja setelah lulus. Sementara itu, 82 responden memilih rentangan jawaban peningkatan yang cukup baik, baik dan sangat baik pada pernyataan peningkatan soft skill yang akan diperoleh setelah mengikuti kegiatan MBKM sebagai bekal setelah lulus kuliah nanti.
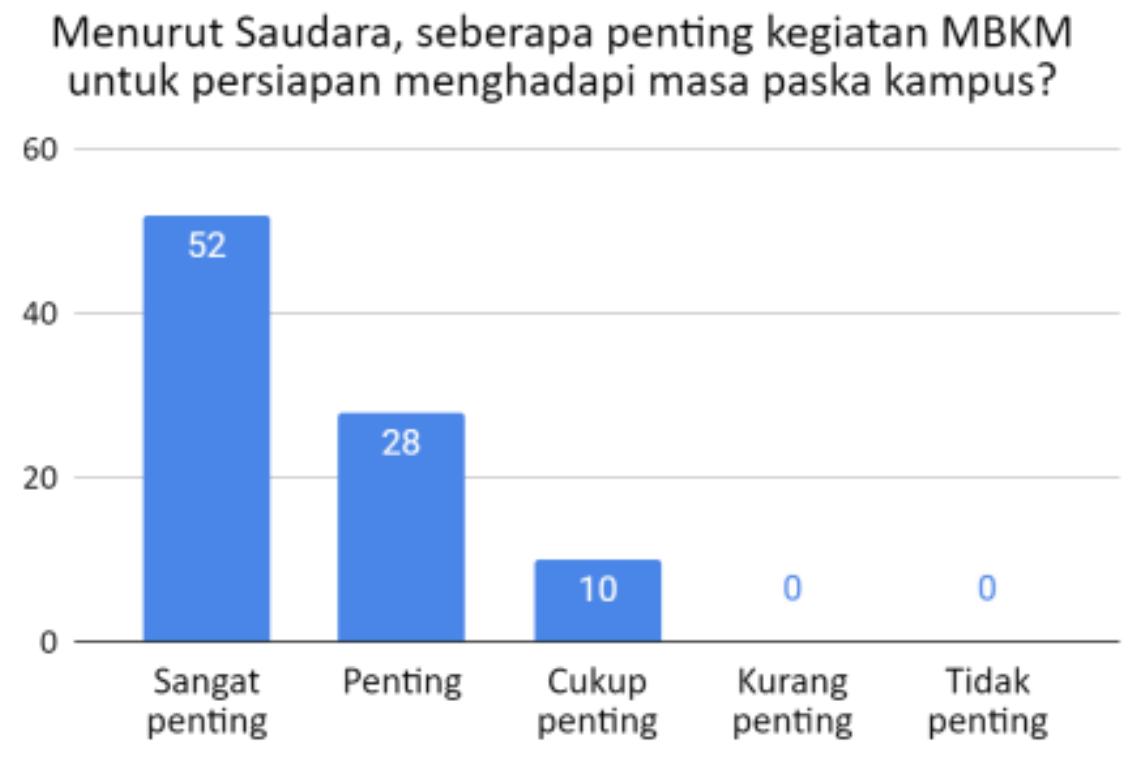

\section{Gambar 6: Hasil Jawaban Survei Mengenai Pentingnya MBKM setelah Lulus Kuliah}

Gambar 6 menunjukan bahwa 100\% responden dari 90 responden memberikan reaksi yang positif pada program MBKM yang diyakini mampu memberikan persiapan yang cukup baik, baik dan sangat baik bagi mahasiswa dalam menghadapi dunia kerja setelah lulus nanti. Hal ini menunjukan harapan dan keyakinan dari mahasiswa bahwa program kebijakan MBKM mampu membawa mereka menghadapi dunia setelah mengakhiri dunia kampus (Wijiharjono, 2021; Latifah, dkk., 2021).

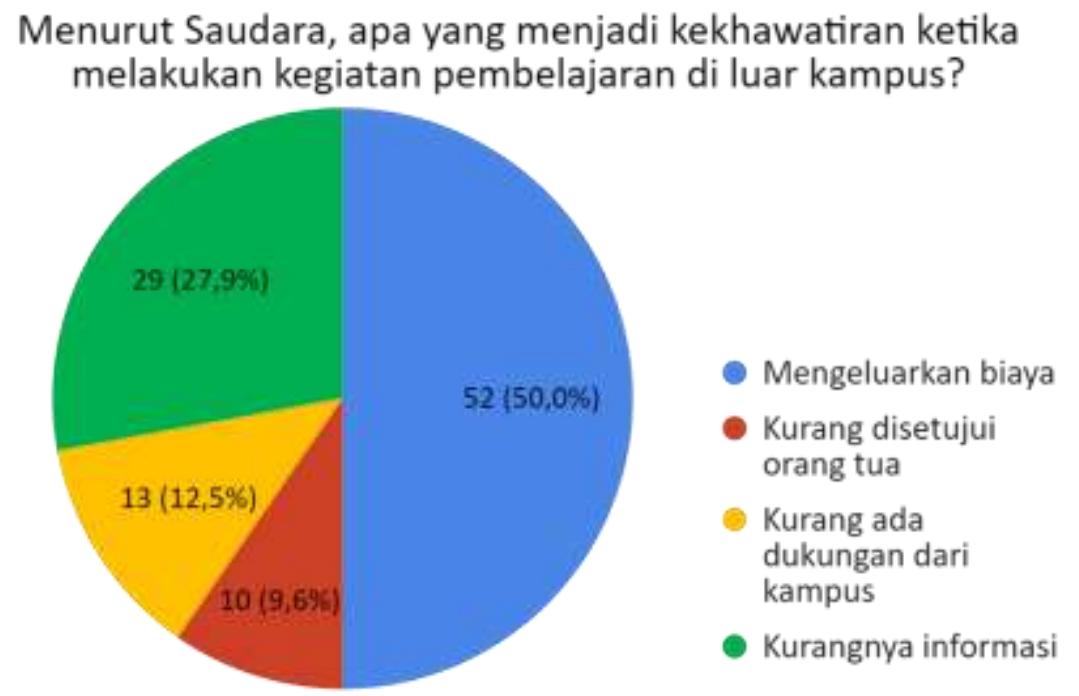

Gambar 7: Diagram hasil survei mengenai hambatan dalam pelaksanaan MBKM 
682 Dampak Kebijakan Merdeka Belajar Kampus Merdeka (MBKM) pada Perguruan Tinggi Swasta di Indonesia - Konstantinus Denny Pareira Meke, Richardo Barry Astro, Maimunah H. Daud

DOI: https://doi.org/10.31004/edukatif.v4i1.1940

Sementara itu, gambar 7 menunjukan hasil survei untuk butir pertanyaan tentang kekhawatiran responden mengenai program MBKM belajar diluar kampus, 50,0\% responden memilih alasan biaya sebagai yang paling dikhawatirkan. Hasil ini tidak mengherankan, karena rata-rata responden mahasiswa berasal dari keluarga yang berkecukupan. Sistem pembiayaan dalam Pendidikan tentu akan memberikan dampak yang besar baik baik atau buruknya kualitas Pendidikan yang bermuara pada peningkatan sumber daya mahasiswa pasca lulus (Mesiono \& Lubis, 2021). Lebih lanjut kurangnya informasi menjadi pilihan terbanyak kedua. Hal ini sejalan dengan pilihan mahasiswa pada gambar 1 yang menjelaskan bahwa mahasiswa sebagai responden menjawab mengetahui sedikit tentang MBKM. Kurangnya Informassi juga terlihat pada butir survei mengenai pertanyaan pengetahuan siswa mengenai keberadaan kebijakan program MBKM pada program studi biologi. 50\% responden mahasiswa menjawab tidak mengetahui tentang kebijakan merdeka belajar di program studi Pendidikan biologi.

Sosialisasi yang lebih mengenai MBKM perlu dilaksanakan oleh baik perguruan tinggi, maupun program studi. Desain program kebijakan MBKM menjadi salah satu metode yang diharapkan memnuhi tantangan program studi pendidikan biologi Universitas Flores untuk menciptakan output yang melek akan kemajuan Peningkatan IPTEK, dan mampu bersaing dalam kemajuan global (Krisnanik, Saphira \& Indriana, 2021; Nehe, 2021). Program MBKM memberi kebebasan dan otonomi kepada lembaga pendidikan untuk memberikan peluang kepada mahasiswa untuk memilih bidang yang mereka minati. Kampus merdeka diharapkan dapat menjadi pembelajaran yang otonom dan fleksibel sehingga tercipta kultur belajar yang inovatif dan sesuai dengan kebutuhan mahasiswa (Rodiyah, 2021; Rohiyatussakinah, 2021).

Respon yang positif ditunjukan oleh responden dalam penelitian ini, menunjukan bahwa mahasiwa tertarik untuk mengikuti banyak program yang ada pada kebijakan MBKM. Mahasiswa menjadi lebih peduli terhadap apa yang hharus mereka persiapkan dimasa depan (Mariati, 2021).

\section{KESIMPULAN}

Hasil dari penelitian survey ini menunjukan bahwa mahasiswa program, studi pendidikan biologi, FKIP Universitas Flores memberikan respon yang positif terhadap program Merdeka Belajar Kampus Merdeka (MBKM). Platform sosialisasi baik daring maupun luring oleh Perguruan Tinggi menjadi platform yang paling dipilih oleh siswa dalam mengtahui semua program dan kebiajakan MBKM, dominan siswa telah menyiapkan diri untuk siap mengikuti program MBKM. Program magang menjadi program MBKM yang paling dominan diminati mahasiswa karena berhubungan dengan link and match terhadap dunia kerja setelah kuliah. Sementara itu, masalah finansial menjadi yang paling dikhawatirkan mahasiswa dalam mengikuti kegiatan MBKM. Banyak saran yang juga dituliskan oleh mahasiswa yakni agar program MBKM dapat diterapkan pada semester awal perkuliahan.

\section{UCAPAN TERIMA KASIH}

Ucapan terima kasih disampaikan kepada Direktoral Jendral Pendidikan Tinggi, Riset dan Teknologi, Kementrian Pendidikan, Kebudayaan, Riset dan Teknologi yang telah mendanai penelitian dampak MBKM ini melalui program penelitian MBKM dan pengabdian berbasis riset menggunakan bantuan pendanaan program penelitian kebijakan Merdeka Belajar Kampus Merdeka dan pengabdian kepada masyarakat berbasis hasil penelitian perguruan tinggi swasta tahun 2021. Ucapan terima kasih juga disampaikan kepada Universitas Flores dan Lembaga Penelitian dan Pengabdian Kepada Masyarakat (LP2M) Universitas Flores yang memberikan kesempatan kepada tim peneliti untuk melakukan penelitian ini. 
683 Dampak Kebijakan Merdeka Belajar Kampus Merdeka (MBKM) pada Perguruan Tinggi Swasta di Indonesia - Konstantinus Denny Pareira Meke, Richardo Barry Astro, Maimunah H. Daud

DOI: https://doi.org/10.31004/edukatif.v4i1.1940

\section{DAFTAR PUSTAKA}

Aji, R. H. S. \&Putra, M. H. I. (2021). Role Model Implementasi Kurikulum Merdeka Belajar Kampus Merdeka Pada Program Studi Non-Agama. SALAM: Jurnal Sosial Dan Budaya Syar-I, 8(6). Https://Doi.Org/10.15408/Sjsbs.V8i6.23821

Arikunto, S. (2010). Prosedur Penelitian : Suatu Pendekatan Praktik (Edisi Revisi). Jakarta: Rineka Cipta

Aswita, D. (2021). Merdeka Belajar Kampus Merdeka (MBKM): Inventarisasi Mitra Dalam Pelaksanaan Magang Mahasiswa Fakultas Keguruan Dan Ilmu Pendidikan. Prosiding Seminar Nasional Biotik, 9(1). 201-206

Baharuddin, M. R. (2021). Adaptasi Kurikulum Merdeka Belajar Kampus Merdeka (Fokus: Model MBKM Program Studi). Jurnal Studi Guru Dan Pembelajaran, 4(1), 195-205. Https://Doi.Org/10.30605/Jsgp.4.1.2021.591

Bethlehem, J. (2009). Applied Survey Methods: A Statistical Perspective. Hoboken: John Wiley \& Sons, Inc. Https://Doi.Org/10.1002/9780470494998

Fatah, Amir. (2021). Eksplorasi Dukungan Industri Mitra Dalam Pelaksanaan Magang Pada Program Merdeka Belajar Kampus Merdeka. Prosiding Seminar Nasional Teknologi Pembelajaran Universitas Negeri Malang Tahun 2021. 1(1), 282-290

Fuadi, T. M. (2021). Konsep Merdeka Belajar-Kampus Merdeka (Mbkm) : Aplikasinya Dalam Pendidikan Biologi. Prosiding Seminar Nasional Biotik, 9(1), 183-200

Fuadi, T. M. \& Aswita, D. (2021). Merdeka Belajar Kampus Merdeka (Mbkm) : Bagaimana Penerapan Dan Kedala Yang Dihadapi Oleh Perguruan Tinggi Swasta Di Aceh. Jurnal Dedikasi Pendidikan, 5(2), $603-$ 614

Intan Dzikria, \& Luvia Friska Narulita. (2021). Pengembangan Kurikulum Untuk Pembentukan Jurusan Sistem Informasi Untag Surabaya Berbasiskan Kurikulum MBKM Dan ACM IS Dengan Metode Kualitatif. Proceeding KONIK (Konferensi Nasional Ilmu Komputer), 5(1), 229-234. Diambil Dari Https://Prosiding.Konik.Id/Index.Php/Konik/Article/View/56

Junaidi, Aris, Dkk. (2020). Panduan Penyusunan Kurikulum Pendidikan Tinggi Di Era Industri 4.0 Untuk Mendukung Merdeka Belajar-Kampus Merdeka. Jakarta: Direktorat Jendral Pendidikan Tinggi Kementrian Pendidikan Dan Kebudayaan

Kamalia, P., \& Andriansyah, E. (2021). Independent Learning-Independent Campus (MBKM) In Students' Perception. Jurnal Kependidikan: Jurnal Hasil Penelitian Dan Kajian Kepustakaan Di Bidang $\begin{array}{llll}\text { Pendidikan, Pengajaran Dan } & \text { 857-867. }\end{array}$ Doi:Https://Doi.Org/10.33394/Jk.V7i4.4031

Krisnanik, E., Saphira, Q., \& Hesti Indriana, I. (2021). Desain Model MBKM Dan Kolaborasi Kerja Sama Model Pentahelix Guna Meningkatkan Daya Saing Lulusan. Proceeding KONIK (Konferensi Nasional Ilmu Komputer), 5(1), 138-142. Diambil Dari Https://Prosiding.Konik.Id/Index.Php/Konik/Article/View/40

Kurnia, Dkk. (2021). Pangan Fungsional Untuk Proyek Independen KKN-Tematik Di Masa Pandemi Covid19. Selaparang.Jurnal Pengabdian Masyarakat Berkemajuan. 5(1), 608-615. Https://Doi.Org/10.31764/Jpmb.V5i1.5749

Latifah, S., Dkk. (2021). Pertukaran Pelajar Unram-UPM : Inovasi Pembelajaran Mbkm Dalam Menumbuhkan Ketangguhan Lulusan Sarjana Kehutanan. Jurnal Perpadu, 2(1), 46-51

Mariati, M. (2021). Tantangan Pengembangan Kurikulum Merdeka Belajar Kampus Merdeka Di Perguruan Tinggi. Prosiding Seminar Nasional Teknologi Edukasi Dan Humaniora 2021, Ke-1. 1(1), 747-758. Https://Doi.Org/10.53695/Sintesa.V1i1.405 
684 Dampak Kebijakan Merdeka Belajar Kampus Merdeka (MBKM) pada Perguruan Tinggi Swasta di Indonesia - Konstantinus Denny Pareira Meke, Richardo Barry Astro, Maimunah H. Daud

DOI: https://doi.org/10.31004/edukatif.v4i1.1940

Mesiono, M., \& Lubis, R. R. (2021). Manajemen Finansial Pendidikan Di Indonesia (Diskursus Sistem Perpajakan Pada Institusi Pendidikan). Al-Fikru: Jurnal Ilmiah, 15(1), 14-27. Https://Doi.Org/10.51672/Alfikru.V15i1.21

Nasik, K. (2020). Model Pembelajaran Mata Kuliah Keislaman Berbasis Masalah Komunitas Yang Terintegrasi Sebagai Langkah Menyikapi Merdeka Belajar Dan Kampus Merdeka (MBKM). Madinah: Jurnal Studi Islam, 7(2), 76 - 87. Retrieved From Http://Ejournal.IaiTabah.Ac.Id/Index.Php/Madinah/Article/View/541

Nehe, B. M. (2021). Analisis Konsep Implementasi Merdeka Belajar - Kampus Merdeka Dalam Mengahadapi Era Revolusi Industri 4.0 Di Masa Pendemik Di Stkip Setia Budhi Rangkasbitung 2021. Prosiding Seminar Nasional Pendidikan Setia Budhi, l(1), 13-19. Diambil Dari Http://Jurnal.Stkipsetiabudhi.Ac.Id/Index.Php/Prosiding/Article/View/18

Putri, R. A., Dkk. (2021). Analisis Kompetensi Guru Mahasiswa Pendidikan Bahasa Dan Sastra Indonesia Universitas Negeri Medan Dalam Program Magang Kependidikan Mbkm. Bahas,32(4), 371-384. Https://Doi.Org/10.24114/Bhs.V32i4.30546

Rochana, R. Darajatun, R. M. \& Ramdhany, M.A. (2021). Pengaruh Implementasi Kebijakan Kampus Merdeka Terhadap Minat Dan Keterlibatan Mahasiswa. Journal Of Business Management Education 6(3) 11-21. Https://Doi.Org/10.17509/Jbme.V6i3.40165

Rodiyah, R. (2021). Implementasi Program Merdeka Belajar Kampus Merdeka Di Era Digital Dalam Menciptakan Karakter Mahasiswa Hukum Yang Berkarakter Dan Profesional. Seminar Nasional Hukum Universitas Negeri Semarang, 7(2), 425-434. Https://Doi.Org/10.15294/Snhunnes.V7i2.737

Rohiyatussakinah, I. (2021). Implementation Of MBKM And The Relationship Of Curriculum Policy Based On A Case Of EFL Education In Japan. Journal Of English Language Teaching And Literature (JELTL), 4(2), 39 - 50. Https://Doi.Org/10.47080/Jeltl.V4i2.1

Rosmiati, R., Putra, I. \& Ahmad Nasori, A. (2021). Pengukuran Mutu Pembelajaran Di FKIP UNJA Dalam Upaya Membangun Generasi Economic Citizen Yang Mengelaborasi Program MBKBM Kemendikbud. Edukatif : Jurnal Ilmu Pendidikan,3(6), 5256 - 5264. Https://Doi.Org/10.31004/Edukatif.V3i6.1356

Salinan Keputusan Menteri Pendidikan Dan Kebudayaan Nomor 754/P/2O2O Tentang Indikator Kinerja Utama Perguruan Tinggi Negeri Dan Lembaga Layanan Pendidikan Tinggi Di Lingkungan Kementerian Pendidikan Dan Kebudayaan Tahun 2020

Sodik, J., Purwiyanta \& Wijayanti, D. L. (2021). Research Synergy Foundation Village Economic Potential For The Implementation Of Learning Building Village / KKN Thematic MBKM Program Economic Study Program Development Department Of Economics, Faculty Of Economics And Business Of The UPN "Veteran" Yogyakarta. RSF Conference Series: Business, Management And Social Sciences. 1(3). 179-184. Https://Doi.Org/10.31098/Bmss.V1i3.317

Sopiansyah, D., Masruroh, S., Zaqiah, Q., \& Erihadiana, M. (2021). Konsep Dan Implementasi Kurikulum MBKM (Merdeka Belajar Kampus Merdeka). Reslaj: Religion Education Social Laa Roiba Journal, 4(1), 34-41. Https://Doi.Org/10.47467/Reslaj.V4i1.458

Suwandi, S. (2020). Pengembangan Kurikulum Program Studi Pendidikan Bahasa (Dan Sastra) Indonesia Yang Responsif Terhadap Kebijakan Merdeka Belajar-Kampus Merdeka Dan Kebutuhan Pembelajaran Abad Ke-21. Dalam: Prosiding Seminar Daring Nasional: Pengembangan Kurikulum Merdeka Belajar Program Studi Pendidikan Bahasa Indonesia, 21 Oktober 2020, Pp 1-12. Https://Ejournal.Unib.Ac.Id/Index.Php/Semiba/Article/View/13356

Syarifuddin, Dkk. (2021). Dosen Penggerak Dalam Era MBKM. Gorontalo: Pascasarjana Universitas Negeri Gorontalo

Wijiharjono, N. (2021, July 11). Akreditasi Perguruan Tinggi Dan Kebijakan Merdeka Belajar-Kampus Merdeka: Sebuah Pengalaman Dan Harapan. Https://Doi.Org/10.31235/Osf.Io/F9smv 
685 Dampak Kebijakan Merdeka Belajar Kampus Merdeka (MBKM) pada Perguruan Tinggi Swasta di Indonesia - Konstantinus Denny Pareira Meke, Richardo Barry Astro, Maimunah H. Daud

DOI: https://doi.org/10.31004/edukatif.v4i1.1940

Zunaidi, A., Naning Fatmawatie, Sri Anugerah Natalina, \& Imam Annas Mushlihin. (2021). Penguatan Pemahaman Dan Orientasi Kurikulum Kampus Merdeka Dalam Menyambut Merdeka Belajar-Kampus Merdeka. Batuah: $\quad J u r n a l \quad$ Pengabdian Kepada Masyarakat, 1(2), $1-7$. Https://Doi.Org/10.33654/Batuah.V1i2.1361 